\title{
Estratégias de letramentos: alfabetização, arte e tecnologia
}

\author{
Maria Cristina da Rosa Fonseca da Silva* \\ Geovana Mendonça Lunardi Mendes** \\ Giani Magali S. Oliveira***
}

\begin{abstract}
Resumo: O presente artigo tem como objetivo relatar os resultados da análise de uma oficina de Letramento e Estética que desenvolveu um conjunto de atividades articuladas ao uso do computador como ferramenta de inovação com nove crianças, sendo quatro delas com deficiência intelectual e outras cinco sem diagnóstico de deficiência intelectual. A oficina propôs uma metodologia própria com dois momentos, um primeiro a partir de contação de histórias e um segundo voltado para a interação com o computador. Como principais resultados, pudemos identificar a formação de um grupo mais coeso e perceber como, nas atividades de uso do computador, as diferenças intelectuais foram sendo minimizadas. Outro aspecto relevante foi o conjunto de objetos pedagógicos criados para o trabalho, tanto com o computador quanto nas atividades estéticas e de contação de histórias.
\end{abstract}

Palavras-chaves: Letramento, Estética, Tecnologia, Deficiência Intelectual

\begin{abstract}
The goal of the present article is to show the results of the analyses from a literacy and arts workshop which developed a series of activities addressed to technology done with nine (9) children, including among them four (4) intellectually disabled ones and five (5) others that were not diagnosed as intellectually disabled. It was proposed through this workshop an appropriated methodology presented by two moments, one through story telling and the other one through computer interaction. We were able to identify as main results two more uniform groups where the intellectual differences were minimized. Another relevant aspect was the amount of the pedagogical tools used during the workshop not only with the arts activities and story telling as well.
\end{abstract}

Keywords: Literacy, arts, technology, intellectual disability.

\section{Situando o estudo}

Ainda hoje, inúmeros são os estudos que abordam as complexidades decorrentes do processo de alfabetização de crianças em idade escolar. Quando essas crianças têm alguma peculiaridade em seu percurso de desenvolvimento, como no caso de crianças com deficiência, as dificuldades de planejar e organizar tal processo se intensificam e muitas vezes parecem intransponíveis. Nossa escolha pelo eixo Informática e Educação Especial se deve às contribuições do processo de

\footnotetext{
* Professora Dra. da UDESC

** Mestre em Educação

*** Estudante de Mestrado em Educação
} 
introdução da informática nas atividades desenvolvidas na oficina Estética ${ }^{1}$ e Letramento. Consideramos nesse processo alguns objetivos. Entre eles destacamos: a) ampliar o desejo entre as crianças de expandir seu nível de letramento, b) desenvolver suas experiências estéticas ampliando a educação do olhar artístico/estético e c) construir novas perspectivas a partir da relação entre letramento e informática. Objetivando enfrentar tais desafios, o presente texto apresenta as experiências desenvolvidas em um projeto de pesquisa intitulado Laboratório de Educação Inclusiva: Metodologias de Inclusão ${ }^{2}$ que desenvolveu três oficinas no período de 2008 a 2010,. O principal objetivo do projeto foi o de criar materiais pedagógicos e desenvolver metodologias de ensino para o trabalho junto a crianças com deficiência, tendo como tema transversal a arte.

Especificamente neste texto abordaremos alguns dos resultados alcançados com a oficina de Estética e Letramento. As atividades realizadas foram organizadas em grupos pequenos, entre oito e dez alunos, divididos por tema e deficiência ${ }^{3}$. Em todas elas foram envolvidos, também, alunos comuns de escola regular a fim de que, mesmo com um número menor de alunos, as atividades pedagógicas pudessem aproximar-se da realidade da escola. É necessário ressaltar que, mesmo com o convite para participação de qualquer criança em fase de alfabetização, a escola envolvida neste processo optou por enviar as crianças que apresentavam dificuldades no processo de letramento. Da mesma forma, foram convidados os estudantes participantes da Associação de Pais e Amigos dos Excepcionais - APAE da cidade de Florianópolis que trabalha com crianças com diagnóstico de Deficiência Intelectual e que apresentam trajetórias com insucesso no processo de letramento.

O planejamento para essa oficina contemplou dois momentos diferenciados, a fim de motivar o conjunto de estudantes e auxiliar no processo de alfabetização. Buscou-se, assim, um momento de contação de histórias, a fim de trabalhar as concepções de formação do grupo e aproximação das relações, e um

\footnotetext{
${ }^{1}$ Tomamos o termo estética/estético do ponto de vista das sensações no campo da sensibilidade, da subjetividade, da experiência sensório-cognitiva surgida da relação entre o sujeito e o objeto artístico/estético mediado pela realidade histórico-social.

${ }^{2} \mathrm{O}$ projeto recebeu recursos da FAPESC (Fundação de Amparo à Pesquisa do Estado de Santa Catarina) e do CNPq (Conselho Nacional de Desenvolvimento Científico e Tecnológico) através de Bolsa(s) de Apoio Técnico.

${ }^{3}$ A primeira oficina envolveu 4 crianças surdas e 6 ouvintes. A segunda abarcou 4 crianças cegas e 4 crianças videntes. Já da terceira oficina participaram 4 crianças com déficit intelectual e 4 crianças sem diagnóstico de déficit intelectual.
} 
segundo momento onde o fio condutor fosse direcionado para as possibilidades de aprendizagem a partir do computador. Conforme aponta Wiggrs: " [...] nas sociedades contemporâneas, os mitos eletrônicos se destacam na rede simbólica, em comparação, por exemplo, com brinquedos, histórias infantis e músicas" (2008, p. 78). Deste modo, a rede simbólica da criança contemporânea está recheada dos elementos retirados das mídias e das tecnologias atuais presentes em seu cotidiano. Nossa hipótese de trabalho era de que o uso do computador, como estratégia de aprendizagem e de trabalho colaborativo, poderia auxiliar significativamente o processo de alfabetização de todas as crianças, em especial, daquelas com deficiência.

É inegável o interesse que as tecnologias em geral provocam nas crianças. Da mesma forma, o computador exerce fascínio em crianças muito pequenas e em adolescentes que, na atualidade, utilizam por muito tempo as ferramentas disponíveis para contato, em especial as redes virtuais de relacionamento ${ }^{4}$. Pela experiência do grupo de pesquisa com o uso de tecnologias na formação de professores, foi possível diagnosticar o interesse das crianças pelas ferramentas disponíveis no computador. Igualmente, o uso do computador possibilitou inserir outros atributos como o uso de cores, imagens virtuais, consultas e pesquisas em determinados programas.

No contexto do letramento, incluímos as reflexões estéticas a partir da obra do artista Ernesto Meyer Filho, que retrata o contexto cultural de Florianópolis, capital de Santa Catarina. A obra do artista, de influência modernista, apresenta um universo mítico e enfatiza uma linguagem diferenciada na aplicação da pintura como meio de expressão. As cores e as formas propostas por ele exercem fascínio sobre as crianças. Cabe ressaltar que os conteúdos de arte, tecnologia e letramento foram articulados na oficina de forma que as linguagens verbal, pictórica e tecnológica tivessem um espaço igualitário dentro da proposta programática. Nesse caso buscou-se não sobrepor uma linguagem a outra, mas, de fato, articular seus conteúdos a fim de conquistar uma interação com o grupo. Nessa proposta, ainda no campo da articulação das linguagens, foi proporcionada aos estudantes uma visita a uma exposição de arte no espaço cultural do Museu Histórico de Santa

\footnotetext{
${ }^{4}$ Não é objetivo deste artigo tratar do tema dos adolescentes e sua relação com a tecnologia, mas esse é um importante tema de pesquisa buscando compreender como se constroem as redes de relação a partir da Internet com público adolescente.
} 
Catarina, a fim de conhecer a obra do artista catarinense Franklin Cascaes ${ }^{5}$, que, também como Meyer Fillho, trabalha a mitologia ilhoa a partir de desenhos, objetos e cerâmicas, além de textos literários. Cada artista guarda uma poética diferenciada, não só do ponto de vista do modo com que trata a mitologia ilhoa, mas também na construção técnica da pintura.

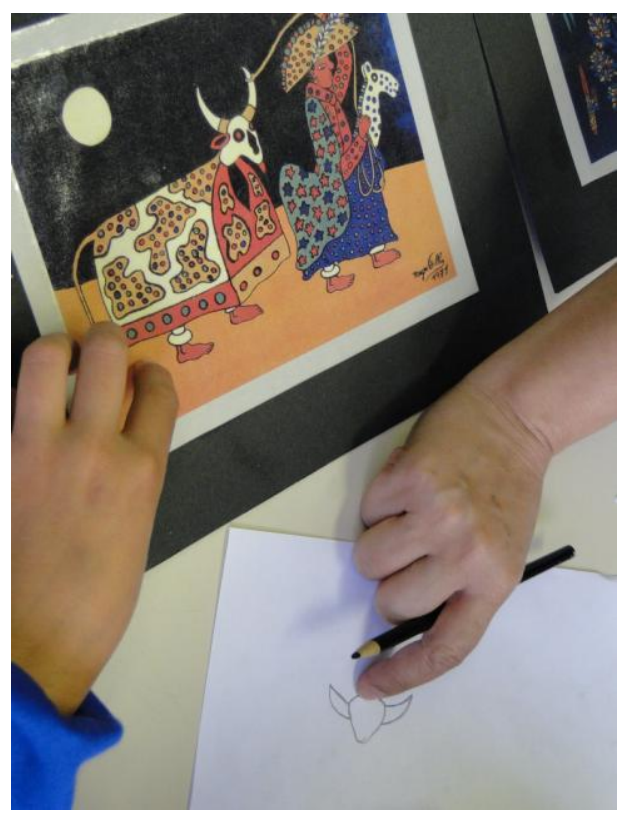

Figure 1 - Atividade de artes a partir da obra de Mayer Filho

Finalmente, introduzimos o tema proposto a fim de ressaltar nessa experiência os objetos pedagógicos criados e utilizados pela professora oficineira como o Baú das Letras, o caderno de atividades, as ilustrações, desenhos, textos e os exercícios desenvolvidos no computador. Após essa sintética apresentação, o tópico 2 relatará a experiência do primeiro momento dos encontros com as crianças e o tópico 3 abordará as atividades desenvolvidas na sala de computação. Já no tópico 4, pretendemos apresentar a análise dos principais resultados.

\section{A oficina de Alfabetizações, Estética e Letramento}

Compreender o código linguístico envolve processos cognitivos complexos. Ressignificá-lo e ampliar seu potencial não é tarefa fácil para quem

\footnotetext{
${ }^{5}$ A exposição contou com a intervenção de artistas contemporâneos que realizaram intervenções no espaço físico da atividade, construindo interações entre sua poética e a de Franklin Cascaes.
} 
aprende, como também para quem ensina. As atividades pedagógicas desenvolvidas para esta oficina contemplaram o brincar e interagir de modo lúdico. Segundo Luckesi (2000, p. 97), lúdicas "são aquelas atividades que propiciam uma experiência de plenitude, em que nos envolvemos por inteiro, estando flexíveis e saudáveis". Para planejar as atividades pedagógicas foram observadas algumas situações. Dentre elas, o fato das crianças pertencerem a dois grupos distintos, um formado por quatro alunos que frequentavam o ensino regular e que apresentavam dificuldades em aprender a ler e escrever, e o outro, constituído por quatro crianças que, além do ensino regular, recebiam atendimento educacional especializado na APAE da região. Inicialmente era preciso envolver os dois grupos para a constituição de uma nova equipe, de forma que "[...] não só o professor que pode ser o mediador entre uma atividade e um aluno que aprende, mas os próprios alunos podem ser mediadores uns dos outros, quando trabalham juntos e compartilham seus conhecimentos." (CAGLIARI, 2006, p. 68). Esse clima de compartilhamento e formação de grupo que foi vivenciado em inúmeras oportunidades durante a oficina - pois tal situação se fazia necessária para romper com o estigma da deficiência como incapacidade -, foi estimulado, possibilitando que cada um se percebesse capaz de ensinar e aprender com seus pares.

O tempo foi outro fator importante no planejamento da oficina. Seriam dez (10) encontros, uma vez por semana, com duração de duas horas cada. Os processos de ensino/aprendizagem adotados precisavam se mostrar eficazes e envolventes. Por este motivo, optamos em trabalhar com a didática para alfabetização "Alfabetizar e encantar: O Mundo das Letras". Esta envolve os interesses das crianças do ponto de vista social e estético, pois " [...] mobiliza recursos cognitivos como os de ouvir, falar, dialogar, ler, escrever, comparar e descrever e com a auto-estima. O aluno interage e estabelece relações sociais com a história e com os outros atores, sente-se parte da sociedade, da história." (OLIVEIRA, 2007, p. 46). Neste processo o brincar faz parte do aprender, ao oportunizar o faz-de-conta e a imaginação em momentos prazerosos, onde os alunos são os atores da sua aprendizagem ao se transformarem em personagens da história que contempla o Rei Alfabeto, suas filhas Princesas (vogais) e filhos Príncipes (consoantes) em um mundo encantado onde as letras possuem vida e formam palavras.

A imaginação, no contexto da oficina e das possibilidades de ampliação do olhar, estabeleceu possibilidades criativas de construção do processo de 
letramento. Segundo Egan (2007), imaginação não é contrária ao pensamento racional; muito diferente dessa posição, a imaginação estabelece novas relações com o contexto e cria ferramentas de ampliação da visualidade e, por consequência, da escrita. Nesse contexto o processo estético não é relativo somente ao contexto da arte por meio da obra de Meyer Filho, mas de toda ampliação do repertório de leitura do mundo a partir da arte, da tecnologia e do letramento.

Pino (2007) destaca que existe uma forte relação entre as ideias estéticas e a história da arte. Do ponto de vista abordado pelo autor, a estética seria uma característica da arte numa íntima relação entre objeto artístico e objeto estético. Embora diferenciando os níveis de experiência, Pino aponta que o sentido constituído no objeto artístico apresenta relação tanto com o autor/artista como com o fruidor/público. No objeto artístico concretiza-se a subjetividade do artista e a do expectador, cada um a partir de seu contexto subjetivo. Bakhtin (2006) traz para o contexto da literatura a problemática do encontro entre o autor e o público responsável por produzir o olhar excedente, aquele que completa o processo de produção da obra, que realiza o acabamento.

O letramento não poderia estar dissociado das práticas pedagógicas de alfabetização, pois, segundo Tfouni (1995) e Kleiman (1995), letramento são as práticas sociais de leitura e de escrita, para além da aquisição do sistema de escrita, ou seja, para além da alfabetização. A diversidade de gêneros textuais trazidas no Baú das Letras ofertou aos alunos situações completas de produções estéticas e concretas de letramento através das coroas, letras, livros, jornais, músicas, imagens, desenhos e histórias, o que aproximou as crianças da leitura e da escrita. Assim, o letramento se fortaleceu e estabeleceu relações com o ensino de arte. Destaca-se que, no caso da oficina, a prática de ensino de arte foi muito próxima da realidade das escolas públicas, situação em que o professor de classe (pedagogo) é o responsável pelo ensino de todas as disciplinas.

Ao início de cada encontro, os integrantes da oficina relatavam suas vivências pessoais, pois "os relatos de experiência pessoal são considerados um importante espaço de construção social do eu." (GIRARDELLO, 2007, p. 52). E alguns alunos, mesmo os não alfabetizados, liam histórias para os colegas, assim como apresentavam suas ilustrações e discussões sobre as imagens de arte ou mesmo a visita ao espaço expositivo. Segundo Soares (2001, p. 47), um sujeito 
pode ser analfabeto, contudo, pode adquirir um certo grau de letramento devido a sua experiência de conviver em uma sociedade letrada.

A autora utiliza como exemplo um adulto que não aprendeu a ler e escrever, todavia, utilizava a escrita para escrever uma carta através de outro indivíduo alfabetizado, um escriba. E enfatiza que é o analfabeto quem dita o seu texto, carregado de suas particularidades. Outro exemplo apresentado é o caso de uma criança que, mesmo antes de ser alfabetizada, tem contato com o mundo letrado através de livros, revistas, ouve histórias lidas por adultos, reconhece imagens, presencia a prática de leitura e escrita, e se interessa por ler, mesmo que seja só "encenação", cria seus próprios textos "lidos" e desenha as histórias ouvidas ou imaginadas. Essa criança pode ser considerada letrada, pois tanto ela, quanto o adulto, mesmo sendo analfabetos, demonstram possuir características de grupos letrados.

Na busca de uma alfabetização estética, as obras do artista Ernesto Meyer Filho (1919-1991) foram apresentadas às crianças desenvolvendo um processo lúdico de leitura da imagem. Nesse processo observou-se que as temáticas eram bastante pertinentes ao contexto dos estudantes. O pintor catarinense é reconhecido internacionalmente e nacionalmente pela originalidade de suas obras que contemplam, também, a paisagem do interior da Ilha de Santa Catarina, além da cultura presente na cidade de Florianópolis "[...] recriando-a, porque eu não sou inventor. Dou à paisagem um sentido mágico, já que a nossa Ilha de Santa Catarina é fantástica e pode me fornecer muitos elementos. Então, eu procuro esse sentido fantástico e surrealista para a pintura da minha paisagem." (DAMIÃO, 1980, p. 16). Auto-proclamado "embaixador artístico de Marte na Terra", Meyer Filho tem o fantástico presente nas suas obras e a sua coletânea "O Boi de Mamão" foi apresentada e discutida com os alunos.

Pillar (2001, p. 15) contribui ao dizer que:

Ler uma obra seria, então, perceber, compreender, interpretar a trama de cores, texturas, volumes, formas, linhas que constituem uma imagem. Perceber objetivamente os elementos presentes na imagem, sua temática, sua estrutura. No entanto, tal imagem foi produzida por um sujeito em determinado contexto, numa determinada época, segundo sua visão de mundo. E esta leitura, esta percepção, esta compreensão, esta atribuição de significados vai ser feita por um sujeito que tem uma história de vida, em que objetividade e subjetividade organizam sua forma de apreensão e apropriação do mundo. 
Ao mesmo tempo, o contexto de vida dos estudantes aponta situações semelhantes ao representado pelo artista e outras experiências urbanas bastante diferenciadas. Como suporte, imagens impressas, livros e músicas folclóricas, além das produções do grupo, como desenhos e dobraduras, trouxeram maior intensidade ao envolvimento das crianças com as obras do artista. Houve ainda uma visita à exposição de Franklin Cascaes, uma oportunidade de levar o grupo de estudantes a um espaço cultural, além de propor diálogos entre as particularidades de cada artista. A maioria deles frequentou o espaço museológico pela primeira vez.

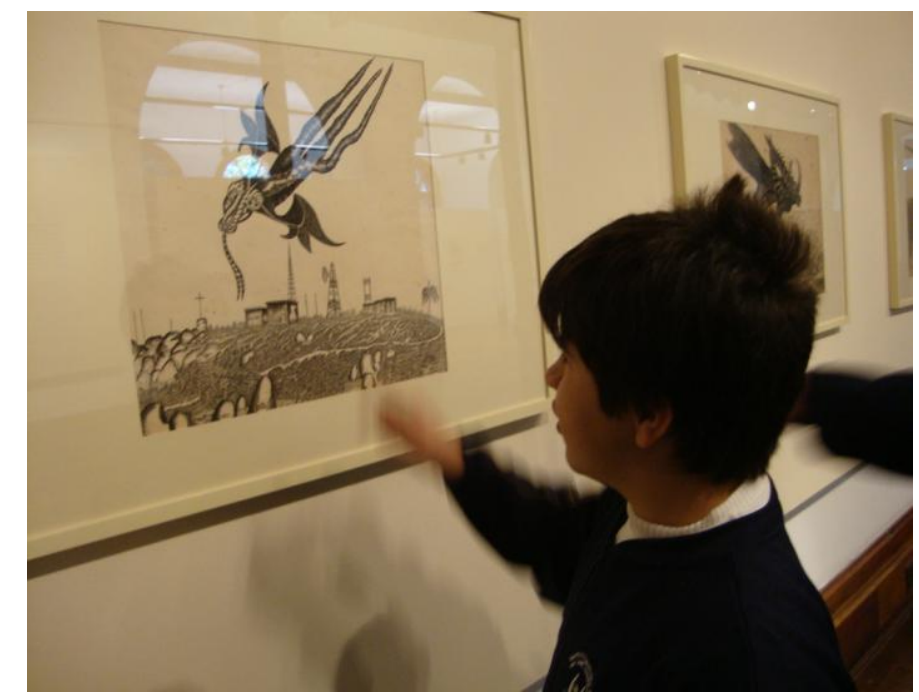

Figure 2 - Visita a exposição de Franklin Cascaes.

Ainda que o desenho seja uma fermenta bastante utilizada na escola, reforçamos sua utilização nesse contexto, pois havia uma intencionalidade de ampliar o acesso das crianças a percepção estética dos elementos constitutivos da obra de Meyer Filho, da análise e reflexão da temática utilizada por ele e suas relações no contexto da arte produzida em Santa Catarina.

A visita aos espaços expositivos e a comparação com a produção artística presente dentro da universidade possibilitou a ampliação do olhar estético das crianças. Quando falavam sobre arte, inicialmente apresentavam conceitos mais tradicionais. Já ao final da oficina, depois da visitação e discussão das produções artísticas, ampliaram seu repertório sobre as artes visuais, o desenho (presente na obra de Franklin Cascaes) e em especial a escultura e os objetos tridimensionais pouco trabalhados no cotidiano da escola. Na exposição de obras de 
Cascaes foram convidados cinco artistas contemporâneos para, a partir da poética do artista, ressignificar sua própria produção. A análise e comparação do processo pictórico dos artistas também alimentou o estudo estético dos estudantes.

Martins, Picosque e Guerra (1998) destacam a capacidade do objeto artístico de afetar o corpo, envolvê-lo no processo de alfabetização estética, proporcionando um processo educativo que considere as experiências estéticas já internalizadas pelos estudantes e propondo novas experiências significativas. 0 contato com a obra de arte no espaço expositivo favoreceu a formação dos participantes da oficina, consolidando o processo de análise das obras, sua relação com o contexto, com os elementos da linguagem visual e com os elementos compositivos. Da mesma forma, o processo de análise histórica e contextualização sedimentou um conjunto de aprendizagens significativas no contexto do ensino de arte trabalhadas ao longo da oficina.

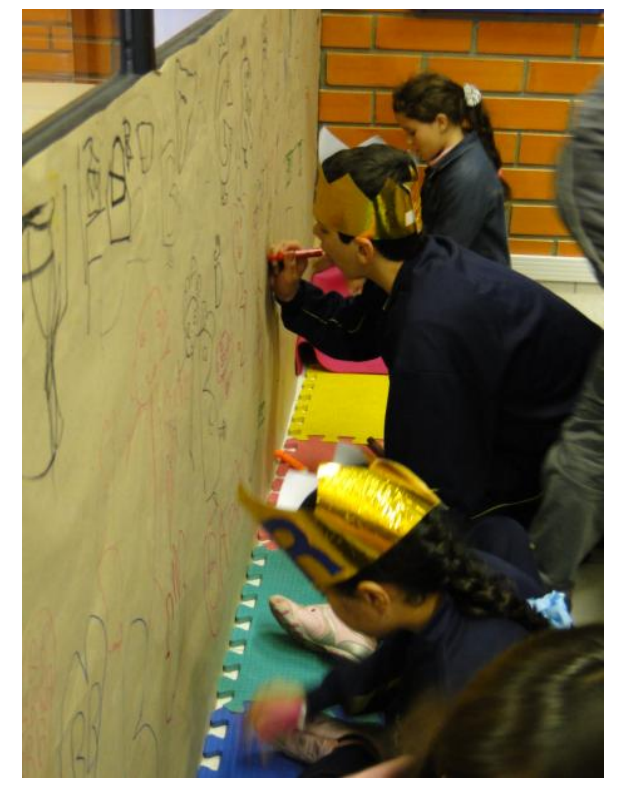

Figure 3 - Atividade estética de reconhecimento do espaço.

As múltiplas linguagens não foram secundarizadas no planejamento desta oficina que as oportunizou em diferentes contextos e instâncias. Vygotsky (1988), ressalta o sujeito como ser complexo carregado de capacidades de leitura social a partir das ações de observar, de atenção, memória e de capacidade de raciocínio. Da mesma forma, cada experiência exitosa em uma das habilidades mobiliza todo o sujeito, ampliando suas potencialidades. 
Uma das relevâncias das oficinas detectada no presente estudo foi a transformação do pensamento convencional, no grupo constituído, de que a criança com deficiência é capaz.

\section{As tecnologias como fio condutor}

Embora tenhamos dividido didaticamente a exposição da oficina em dois momentos, as atividades desenvolvidas constituíram um diálogo entre arte, tecnologia e letramento. Todavia, inquietações permeavam os envolvidos, entre elas, o quanto o letramento digital se fazia presente neste grupo, visto que, a princípio, não tínhamos a informação de que existia um convívio do grupo com os computadores. Nesse cenários as dificuldades impostas aos sujeitos e os desafios impostos por uma sociedade tecnológica solicitaram novos rearranjos a fim de conhecer " $[. .$.$] novas estruturas de comunicação, de regulação e de cooperação,$ linguagens e técnicas intelectuais inéditas, modificação das relações de tempo e espaço etc. A forma e o conteúdo do ciberespaço ainda são especialmente indeterminados." (LÉVY, 2007, p. 13).

Estes confrontos transfiguraram o termo letramento para letramentos. Em relação ao letramento, Soares (2002), destaca a necessidade de construir uma ideia de letramentos, pois o processo mobiliza diferentes e múltiplos efeitos a partir dos contextos onde estão inseridos. A professora destaca outros elementos como parte do letramento como as imagens, o espaço, a sonoridade, ou seja, um conjunto de instrumentos disponíveis na sociedade que possibilitam ampliação dos processos de alfabetização. 


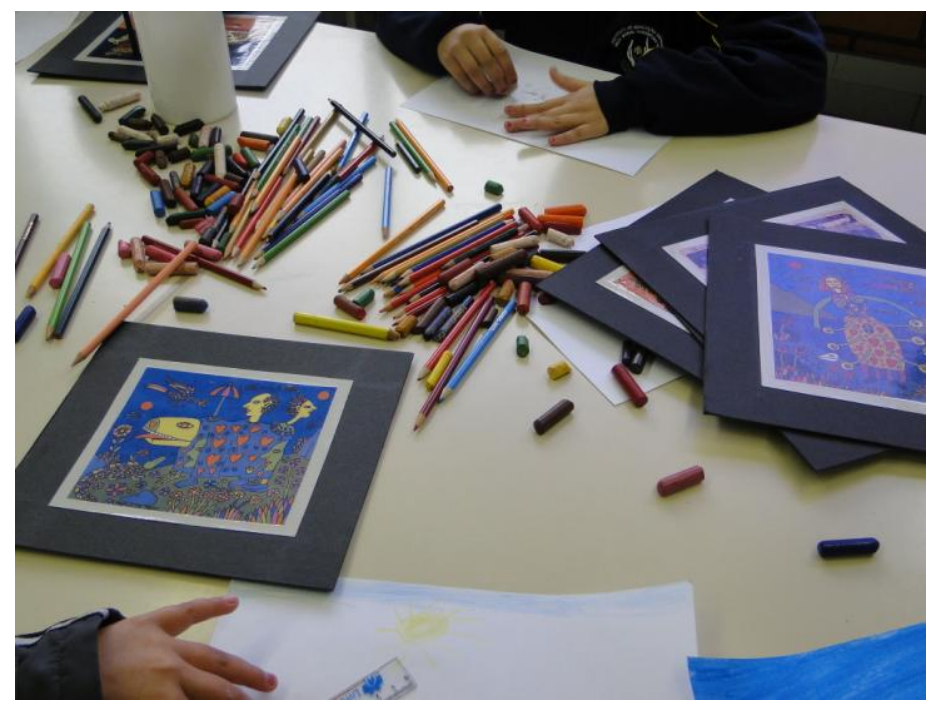

Figure 1 - - Atividade Estética a partir da obra de Mayer Filho.

O letramento digital é um processo complexo de reorganizações e reestruturações de diversos subsistemas, pois apresenta muitas e amplas linguagens, disponibilizadas pelos meios digitais que envolvem imagens, sons, animações e interação in loco em tempo real. Tais possibilidades exigem dos sujeitos outra forma de pensar, construir conhecimento e, consequentemente, de educar, o que propicia, o surgimento de novos ambientes socioculturais.

Imagem, movimento, cor, som, brilho e interação são componentes em um ambiente digital que não passam despercebidos por adultos e crianças. 0 mundo da informática é encantador, envolve, oportuniza, descomplica o fazer cotidiano em empresas, comércios, lanchonetes, consultórios médicos, etc. Calcular, escrever, jogar e brincar com personagens nunca dantes imaginados passou a ser prática diária em muitos ambientes das mais diversas classes sociais. Soares (2002), ao abordar os conhecimentos adquiridos no letramento digital, identifica que o domínio das ferramentas do computador não é o suficiente para ampliar o conhecimento. Outros processos criativos e de ampliação do conhecimento estão envolvidos na formação do leitor. Igualmente na aprendizagem da arte, com destaque para a produção contemporânea, os elementos tecnológicos vêm, ao longo dos anos, ganhando espaço e força no sentido de propor diferentes experiências estéticas. Embora os objetos artísticos produzidos a partir da obra de Cascaes não façam articulação direta com os elementos tecnológicos, abordam um tempo histórico presente que é permeado por culturas tecnológicas. 
O deslocamento do ambiente onde eram iniciados os encontros para o laboratório de informática da instituição já era motivo de alegria. E resolver atividades que envolviam leitura, arte e escrita em outro suporte, no caso o computador, exigia interação e concentração dos alunos, pois "[...] uma mudança material produz efeitos intelectuais que, por sua vez, produzem novos resultados materiais [...] mudança tecnológica e intelectual não são novas na história." (TEBEROSKY, 2004, p. 154).

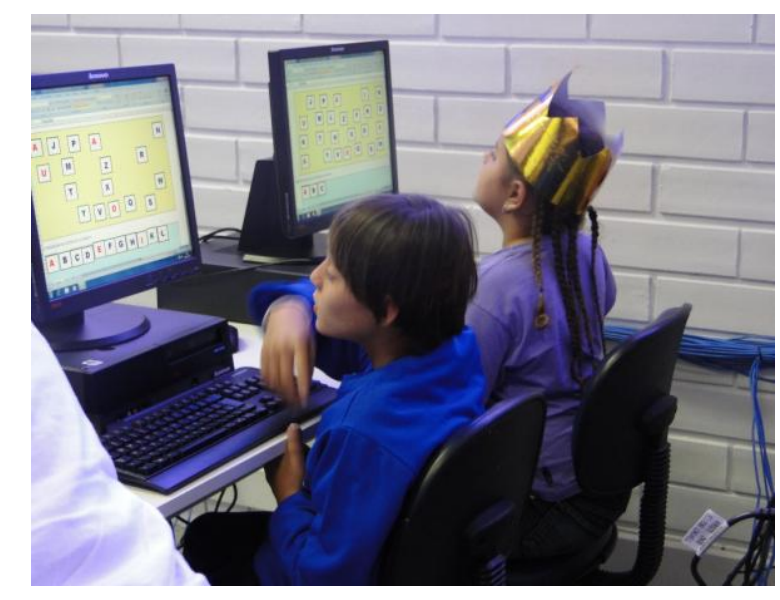

Figure 4 - Atividade de Letramento na sala de informática.

Inicialmente foi disponibilizado o Google Earth ${ }^{6}$ para que os alunos se percebessem integrantes de um grande sistema onde, mesmo sendo muito parecidos, são únicos e importantes. Foi nesta atividade que o letramento digital pôde ser observado, pois a dificuldade não estava em trabalhar no computador, mas sim no manuseio do mouse. Pudemos observar que, nesses sujeitos, o letramento digital apresenta-se em uma versão fraca (SOARES, 2001), na qual o sujeito possui conhecimentos básicos de como acessar as mídias, mas não o suficiente para influenciar transformações socioculturais. Esses conhecimentos básicos oportunizam a participação no ciberespaço e desempenhar suas funções trabalhistas e sociais, porém não possibilitam situar-se como sujeito histórico.

Ao serem questionados sobre como ligar a máquina, todos afirmaram saber, e o fizeram de maneira correta. Para acessar a internet e o programa indicado não apresentaram dificuldades, porém, para direcionarem o mouse nas posições desejadas, alguns alunos demonstram dificuldades. A falta de exercícios

\footnotetext{
6 "O Google Earth permite-Ihe voar para qualquer local na Terra para ver imagens de satélite, mapas, terreno, edifícios em 3D, desde galáxias no espaço até aos desfiladeiros dos oceanos. Poderá explorar conteúdo geográfico complexo, guardar os locais visitados e partilhá-los com outros utilizadores". Informação retirada do site: http://earth.google.com/intl/pt/.
} 
anteriores de domínio do mouse não contemplavam somente os alunos com deficiência intelectual.

[...] o computador pode ser um recurso flexível, passível de ser adaptado às diferentes necessidades de cada indivíduo [...] a ferramenta de trabalho com a qual o aluno resolve problemas, escreve, desenha, etc., essas atividades passam a ser importantes fontes de diagnóstico e avaliação da capacidade intelectual de sujeitos com diferentes tipos de necessidades especiais. (VALENTE, 2001, p. 30)

Em um dos encontros foi solicitado aos alunos que resolvessem uma atividade em folha de papel, mas três alunos com deficiência intelectual, não a realizaram sob a argumentação de "Não sei!" e "Não consigo!". Todavia, no mesmo encontro, essa atividade foi disponibilizada no computador e o discurso mudou. 0 "Não consigo" deu espaço para o "Deixa, que eu faço", e todos a resolveram. Em outra situação, foram lhes oportunizados 15 minutos para acessarem o que desejassem e todos clicaram no ícone da internet. Podemos dizer, então, que a mediação deixou de ser feita pelo professor e foi transferida para os colegas do grupo. Em poucos instantes todos acessavam joguinhos em sites infantis disponibilizados no ciberespaço.

A coleta de dados foi realizada de quatro formas, a saber: 1 - relato no diário de campo realizado pela bolsista de iniciação científica Isadora de Azevedo; 2 - Fotografias dos encontros, 3 - análise de duas horas de filmagens a cada encontro, realizadas pela bolsista Stéfanie da Cunha Rocha; 4 - Diário da professora Giani Oliveira contendo os relatos do ponto de vista da mesma.

Acreditamos que a análise de todas essas peças necessitará um tempo maior, haja vista que a pesquisa foi concluída em julho de 2011 e a íntegra dos dados será analisada em Fonseca da Silva, Mendes e Schambeck (2012). Mas ao mesmo tempo, pelo envolvimento com a pesquisa já nos sentimos motivados a realizar algumas incursões sobre seus resultados. Ressaltamos que, numa abordagem de pesquisa qualitativa, segundo Kincheloe (2008), a formação dos pesquisadores e suas experiências no trato com a análise dos dados é um componente determinante. Portanto, essa investigação não se propõe a aferir resultados que sejam generalizados para outras realidades; nossa análise buscou identificar como se constituíram os processos de aprendizagem considerando os materiais pedagógicos utilizados pela professora. Não só os criados por ela, como as atividades do Baú das Letras, do rei do mundo das letras, ou mesmo, as 
atividades para uso no computador e as pranchas para o trabalho com a obra do Artista Meyer Filho, mas também, a forma como se apropriou dos materiais educativos de alfabetização já existentes no Laboratório.

Os materiais desenvolvidos para crianças com deficiência, como livros tácteis, livros de figuras em relevo e/ou destacadas, foram utilizados pela professora para oferecer um ambiente de letramentos para toda a turma e não só para as crianças com deficiência. Aprofundaremos essa reflexão nas considerações finais.

\section{Arrematando o percurso}

Podemos concluir que a articulação entre arte, tecnologia e alfabetização possibilitou um primeiro encontro de diversos processos de letramentos para os alunos envolvidos na oficina de Estética e Letramento. A entrada da instituição artística, do objeto artístico, da experiência estética, provocou na prática didática um inquietante processo de construção de pontes entre a educação do olhar, a reflexão e a escrita de um repertório de letramento. Igualmente o jogo presente nessa descoberta do conteúdo do Baú de Histórias e na afirmação das singularidades de cada participante da oficina também se tornou presente nas atividades desenvolvidas nos exercícios de letramento no computador e nos materiais produzidos (caderno de escrita, desenhos, histórias criadas em conjunto).

Destacamos, também, a necessária familiarização das crianças com as diversas tecnologias de seu entorno e de que o acesso às mídias presentes no computador se qualifique como um processo crítico. Cresce o número de usuários da internet no Brasil, mas ainda é pequena a formação crítica para, a partir dos materiais encontrados, selecionar o que de melhor qualidade está disponível. Confiamos que as oportunidades criadas na escola para acesso qualificado às informações por meio do computador podem ampliar a visão de mundo dos estudantes. Também o acesso crítico às tecnologias oferece ferramentas de criação on line disponibilizada, por exemplo, nos sites de museus virtuais, ou ainda, nas propostas de artistas que utilizam a internet como espaço de interação e disponibilização de seu trabalho.

Ao analisar o tempo de atividades com as crianças, podemos identificar, como resultado, que dez encontros são insuficientes para que o processo de leitura, escrita e educação estética se instaure com sucesso. Todavia, alguns resultados são possíveis de serem alcançados em relação a outros sentidos que são mobilizados no 
processo educativo. Podemos dizer que a oficina criou um ambiente favorável ao processo de alfabetização estética, tecnológica, e oportunizou o avanço no letramento. Observamos a participação das crianças, a partir dos vídeos realizados, e verificamos as diferenças corporais no início e no final da oficina. Nos primeiros encontros, alguns alunos mostravam-se reticentes em compartilhar o mesmo espaço, as mesmas atividades com crianças com deficiência; havia um preconceito instaurado, o que era percebido em muitos momentos, pois os mesmos sentavamse distantes ou ignoravam pedidos de ajuda. Isso foi resolvido no percurso da oficina, pois ao final da mesma, todos compartilhavam aprendizagens, lanches e brincadeiras. Identificamos nesse sentido, como resultado, que os dez encontros foram suficientes para conquistar um entrosamento entre dois grupos de crianças de realidades diferenciadas que se dispuseram a aprender juntas.

O uso das tecnologias foi importante na resolução das atividades. Estas, em algumas ocasiões, reproduziam situações rotineiras para que os envolvidos a resolvessem com sucesso, pois conseguir concluir uma atividade com êxito é fundamental para desenvolver um percurso prescritivo e sentir-se capaz de aprender, como também para recuperar a autoestima perdida no percurso escolar para alçar outras aprendizagens que mobilizem os aspectos simbólicos e criativos.

Outro resultado observado por meio dos registros de campo foi a interação computador/aluno/grupo. Quando um aluno solicitava ajuda, esta vinha de todas as direções. Até mesmo crianças sentadas distantes se propunham a ajudar. A deficiência deixou de ser vista como um entrave e um dos alunos com deficiência intelectual era o que mais ajudava os colegas na resolução das atividades propostas no computador.

Foi possível identificar que as experiências de contato anterior das crianças com a tecnologia são exitosas. Por que o são com o uso do computador que exige processos complexos - e em outros processos de letramento o desempenho não é o mesmo? Podemos supor ao menos duas hipóteses para isso, que necessitariam ser desenvolvidas em pesquisas posteriores. Uma delas é de que essas crianças tiveram acesso a propostas de ensino por computador que ampliaram seus saberes nessa área, tornando-as autônomas para novas aprendizagens. Outra hipótese é de que, como os professores, de modo geral, dominam pouco as ferramentas tecnológicas em relação às crianças, principalmente no que diz respeito ao medo em relação a ousar na tecnologia, abrir pastas, clicar 
botões, etc., é possível que os estudantes tenham tido experiências mais independentes de uso das tecnologias. Da mesma forma, esse processo trouxe outros modelos de avaliação e libertou os alunos com deficiência dos rótulos e estigmas presentes nos processos comuns de sala de aula.

No tocante às atividades estéticas específicas da arte, as obras de Meyer Filho encantaram as crianças. Foi através dos galos multicoloridos presentes em diversas obras deste artista plástico que descobrimos que um dos alunos, filho de pais analfabetos que sobrevivem como catadores de material reciclável, e que já se percebia incapaz de aprender a ler e escrever, era fascinado por passarinhos e conhecedor profundo das aves da região.

$\mathrm{Na}$ internet este aluno pesquisou sobre a obra de Meyer Filho e sobre alguns pássaros, o que o fez refletir sobre a importância da escrita e da leitura. Seu entusiasmo foi enorme quando conseguiu digitar no Google Imagens a palavra passarinho e inúmeras fotografias apareceram. Seu desejo era de que uma das estagiárias ficasse ao seu lado, lendo cada informação. Em outras palavras, um outro mundo se abriu para essa criança. A experiência de seu cotidiano, aliada à ferramenta tecnológica da internet, possibilitou a ampliação de suas ferramentas expressivas para a construção do desenho e de outras visualidades a partir das imagens descobertas, constituindo um ganho para seu processo de conhecedor e fruidor da produção artística de Meyer Filho, Cascaes e dos artistas participantes da exposição.

Campos (2002) reforça essa análise quando destaca o papel dos extensores visuais, que seriam um conjunto de imagens virtuais e/ou fixas que possibilitam a ampliação do repertório estético das pessoas e que devem permear as propostas educativas no ensino de arte. A autora destaca, também,, que nem sempre existem condições de crítica ao conteúdo e procedência das imagens, dada a quantidade das mesmas "despejada" pelas mídias na sociedade.

A visitação à exposição de Franklin Cascaes foi um grande momento para estes alunos. Nas esculturas de argila, situações folclóricas da Ilha de Santa Catarina, como o carnaval e as bruxas, os estudantes puderam refletir sobre as histórias e o contexto cultural da cidade onde moram. Nos desenhos em nanquim, os dragões suscitaram um mundo de possibilidades imaginativas. Fatos pitorescos sobre a história e a obra de Franklin Cascaes foram narrados aos pequenos pela educadora do Museu, que respondia às indagações e curiosidades dos estudantes. 
Cada pintura e escultura foi olhada e re-olhada com entusiasmo; o desejo era de tocá-las, talvez possuí-las. Ao sair do prédio, os estudantes questionavam quando e como poderiam retornar àquele lugar, o mundo de Franklin Cascaes.

As atividades desenvolvidas com O Mundo das Letras, contação de histórias, músicas e os demais artefatos, envolveram os alunos em brincadeiras e situações que se diferenciam das práticas escolares, situações e espaços não presentes no ambiente da escola. Nossa análise nos auxiliou a identificar que romper com os estigmas do espaço escolar também se mostrou eficaz, porque a escola, em muitas situações, é caracterizada como um ambiente com poucos atrativos, que não contempla os interesses das crianças.

Outro resultado importante foi identificar que a proposta pedagógica da oficina ofereceu a esses sujeitos situações nas quais o aprender pode ser prazeroso e estimulou a construção de uma concepção de aprendizagem destituída de situações normalizadoras e uniformizantes. Acreditamos que a ampliação dos espaços criativos, processuais e investigativos no fazer pedagógico qualificaria os processos de construção do conhecimento.

Finalmente, para a equipe de investigação, a experiência foi exitosa, não só pelas conquistas das crianças com o acesso a um processo de letramento e alfabetização estética e criativa a partir da tecnologia e da arte, mas também por todos os olhares e afetos que se constituíram no processo entre professora, estagiários e as crianças e de tudo que foi possível de aprender com as crianças sobre como elas se relacionam com o aparato da escrita, do uso do computador e do campo das artes visuais.

\section{Referências:}

BAKHTIN, M. Estética da criação verbal. São Paulo: Martins Fontes, 2006.

CAGLIARI, L. C.. A respeito de alguns fatos do ensino e da aprendizagem da leitura e da escrita para crianças na alfabetização. In: ROJO, R. (Org.). Alfabetização e Letramento: perspectivas linguísticas. Campinas, SP: Mercado das Letras, 2006. 
CAMPOS, Neide Pelaez. A construção do olhar estético-crítico do educador. Florianópolis: Editora da UFSC, 2002.

DAMIÃO, C. Meyer Filho, um artista catarinense. Jornal de Santa Catarina. Ed. 14 e 15 de set, 1980.

EGAN, Kieran. Por que a imaginação é importante na educação? In.: FRITZEN, C.; CABRAL, G. S. (Orgs.) Infância: Imaginação e Educação em Debate. Campinas, SP: Papirus, 2007.

GIRARDELLO, G. Voz, Presença e Imaginação: a narração de histórias e as crianças pequenas. In: FRITZEN, C.; CABRAL, G. S. (Orgs.) Infância: Imaginação e Educação em Debate. Campinas, SP: Papirus, 2007.

GOOGLE. O Google Earth.Disponível em< http://earth.google.com/intl/pt/.> Acesso em: out. de 2010.

KINCHELOE, J. L e BERR, Kathleen S. Pesquisa em educação: conceituando a bricolagem. Porto Alegre: Artmed, 2008.

KLEIMAN, A. Modelos de letramento e as práticas de alfabetização na escola. In: KLEIMAN, A. (Org.). Os significados do letramento: uma nova perspectiva sobre a prática social da escrita. Campinas, SP: Mercado de Letras, 1995, p. 15-61.

LÉVY, Pierre. A Inteligência Coletiva: por uma antropologia do ciberespaço. 5 ed. São Paulo: Loyola, 2007.

LUCKESI, C. C. Educação, ludicidade e prevenção das neuroses futuras: uma proposta pedagógica a partir da Biossíntese. In: LUCKESI, C. C. (Org.) Ludopedagogia - Ensaios 1: Educação e Ludicidade. Salvador: Gepel, 2000.

MARTINS, M. C., PICOSQUE, G., GUERRA, M. T. T. Didática do ensino de arte: a língua do mundo: poetizar, fruir e conhecer arte. São Paulo: FTD, 1998.

OLIVEIRA, G. M. S. Alfabetizar e Encantar: O Mundo das Letras. In.: SIMPÓSIO CATARINENSE DE ADMINISTRAÇÃO DA EDUCAÇÃO/AAESC， 19; SEMINÁRIO ESTADUAL DE POLÍTICA E ADMINISTRAÇÃO DA EDUCAÇÃO/ANPAE/SC, 7. 2007. 
Blumenau. Anais eletrônicos... Blumenau. Infância, Currículo e Gestão. Anais do XIX Simpósio Catarinense de Administração da Educação/AAESC; VII Seminário Estadual de Política e Administração da Educação/ANPAE/SC. Blumenau, set. de 2007. Disponível em: http://www.aaesc.com.br/Anais2007.pdf > Acesso em 10 ago. 2010 .

PILLAR, Analice Dutra. A Educação do Olhar no Ensino das Artes. Porto Alegre: Mediação, 2001.

PINO, Angel. Educação estética do sentimento e processo civilizador: um ensaio sobre estética e semiótica. In: ZANELLA, A. V. (Org.) Educação estética e constituição do sujeito: reflexões em curso. Florianópolis: NUP/CED/UFSC, 2007.

SOARES, M.. Letramento: Um tema em três gêneros. Belo Horizonte: Autentica, 2001.

.Novas práticas de leitura e escrita: letramento na cibercultura. Educação e Sociedade, v. 23, n. 81, p. 143-160, dez. 2002.

TEBEROSKY, A. Alfabetização e tecnologia da informação e da comunicação (TIC). In: Contextos de Alfabetização Inicial. Porto Alegre: Artemed, 2004.

TFOUNI, L.V. Letramento e alfabetização. São Paulo: Cortez, 1995.

WIGGERS, I. D. Infância e mídia: crianças desenham novas corporeidades? In: FANTIN, M. e GIRARDELLO, G. Liga, roda, clica: estudos de mídia, cultura e infância. Campinas, SP:Papirus editora, 2008.

VALENTE, J. A. Aprendendo para a vida: o uso da informática na educação especial. In: VAlENTE, J. A., FREIRE, M. P. (Orgs.) Aprendendo para a vida: os computadores na sala de aula. São Paulo: Cortez, 2001.

VYGOTSKY, L. S.; LURIA, A. R. Linguagem, Desenvolvimento e Aprendizagem. São Paulo: Ícone, 1988. 